\title{
OsDREB2A Gene Polymorphism Does Not Affect Salinity Tolerance Potency of Local Rice Varieties from Banten
}

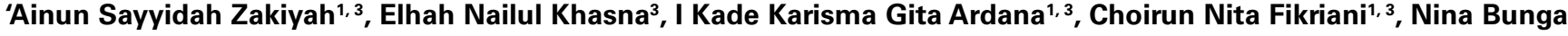 \\ Anggraini ${ }^{1,3}$, Dwita Novitasari ${ }^{1,3}$, Dwi Listyorini ${ }^{1,3,4}{ }^{*}$, Suharti $^{2,3,4}$ \\ ${ }^{1}$ Department of Biology, Faculty of Mathematics and Natural Sciences, Universitas Negeri Malang, Malang, Indonesia \\ ${ }^{2}$ Department of Chemistry, Faculty of Mathematics and Natural Sciences, Universitas Negeri Malang, Malang, Indonesia \\ ${ }^{3}$ Biotechnology Division, Central Laboratory of Mineral and advanced Material, Faculty of Mathematics and Natural Sciences, \\ Universitas Negeri Malang, Malang, Indonesia \\ ${ }^{4}$ PIUPT Disruptive Learning Innovation, Universitas Negeri Malang, Malang, Indonesia
}

\section{ARTICLE INFO}

Article history:

Received October 20, 2020

Received in revised form January 30, 2021

Accepted February 5, 2021

\section{KEYWORDS:}

salinity tolerant rice,

local rice varieties,

OsDREB2A polymorphism

\begin{abstract}
Indonesia possesses vast coastal agricultural land areas with high salinity. This high salinity is a threat to rice productivity which may decrease to $\mathbf{7 9 . 8 \%}$. Banten province of Indonesia houses many local rice varieties which have salinity tolerance potency based on its agronomical characters. The adaptability of rice plant in high salinity soil can be affected by $O s D R E B 2 A$ gene, which encodes transcription factors from several salt-tolerant signaling pathway genes. The aims of this study were to find out the possible polymorphism of $O S D R E B 2 A$ gene from Banten local rice varieties. The polymorphism of $O S D R E B 2 A$ analyzed by Single Nucleotide Polymorphism (SNP) and possible molecular structure. OsDREB2A gene was amplified using DNA from Tambleng, Bulu Putih, and Pare Caok varieties as templates through PCR method with a pair of specific primers. DNA fragments obtained were analyzed by means of series of analysis software. From those analysis we obtained $840 \mathrm{bp}, 836 \mathrm{bp}$, and 850 bp gene fragments from Tambleng, Bulu Putih, and Pare Caok varieties, respectively. There is polymorphism of $O S D R E B 2 A$ due to some mutation yet does not massively alter its protein structure. From this study, we suggest that Tambleng, Bulu Putih, and Pare Caok varieties potential for salinity stress resistance genetically.
\end{abstract}

\section{Introduction}

High soil salinity is one of the major problem in agriculture land. More than 800 billion agricultural lands in the world have high salinity due to errors in irrigation processes, sea levels, and weather. The amount of saline land increasing from year to year (FAO 2003; Abuelgasim and Ammad 2019). Agricultural land with high salinity can disrupt plant growth (Chinnusamy et al. 2006), especially in pollen development and fertilization phases and can decrease that productivity until 79.8\% (Jenks et al. 2007). High salinity conditions trigger plants to carry out defences by activation of certain genes and anatomical changes to survive stress conditions. One of the genes involved in the salt-tolerant signalling pathway in rice (O. sativa) is OsDREB2A. OsDREB2A encode a transcription factor that plays a role in regulating plant responses to abiotic stresses that cause cells to

\footnotetext{
* Corresponding Author

E-mail Address: listyorini.aljabari@um.ac.id
}

become dehydrated through ABA-independent signalling pathways (Sakuma et al. 2002; Dubouzet et al. 2003; Gumi et al. 2018).

OsDREB2A is thought to be used as a marker gene to identify plant resistance to abiotic stress (Rini 2019). The difference in the level of expression or the presence of polymorphisms in the OSDREB2A gene can result in changing the structure of the OsDREB2A protein (Shastry 2009; Matsukura et al. 2010). Changes in the structure of the DREB2 protein are thought to be able to influence plant responses to abiotic stress in the form of drought (Liu et al. 2013). Mutation of DREB2A gene (OsDREB2A) in Indonesian Javanese local rice varieties, can eliminate the ability of $D R E B 2 A(O s D R E B 2 A)$ to bind the cis-regulatory target gene such a $r d 29 A$ (Lathif et al. 2018). Decreasing the ability of OsDERB2A to bind $r d 29 A$ can affect the expression of target genes regulated by OsDREB2A to respond to salinity stress conditions. Based on the abiotic test results it is known that Banten local rice varieties Tambleng, Bulu Putih, and Pare Caok did not show necrosis and growth 
disorders at the age of three weeks after being given salt stress with concentrations of 150 and $200 \mathrm{~mm}$ (RC Biotechnology 2018). The result showed that these varieties potential to be tolerant of salinity stress condition. Rice resistance to saline conditions can also be identified through a molecular approach based on the OsDREB2A gene polymorphism that is related to the response to salinity stress conditions in rice (Rini 2019). The aims of this research are to identify OsDREB2A gene polymorphism in Banten local rice varieties Tambleng, Bulu Putih, and Pare Caok which have the potential to tolerate salinity stress conditions.

\section{Materials and Methods}

This experiment used samples from Banten local rice varieties, there are Tambleg, Bulu Putih, and Pare Caok varieties. Rice sample seeds were germinated at $25^{\circ} \mathrm{C}$ in the dark for 14 days. Total DNA was isolated from leaves tissues using DNeasy ${ }^{\circledR}$ Plant Mini Kit DNA isolation kit (Qiagen). The purity of DNA was examined using NanoDrop ND-2000 Spectrophotometer. The full length of OsDREB2A gene amplified by specific primer ${ }^{5}$ ATG CTG TTT CGA TTT GTG TCT TG ${ }^{3}$ (forward) and ${ }^{5}$ CTA ATA GGA GAA AAG GCT AAA C ${ }^{3}$ (reverse). Amplification process were carried out using PCR Master Mix Solution ( $i$-Taq) (Intron) with PCR amplification condition was as follows pre-denaturation of 2 minutes at $94^{\circ} \mathrm{C}$, denaturation 20 second at $94^{\circ} \mathrm{C}$, annealing of 10 seconds at $46.4^{\circ} \mathrm{C}$, extension at $72^{\circ} \mathrm{C}$ for 45 seconds, final extension at $72^{\circ} \mathrm{C}$ for 3 minutes. The resulted PCR amplified product were separated on $1 \%$ agarose gel then was sequenced to identified full length of OsDREB2A gene.

Sequence polymorphism were analyzed by several software and webserver. The sequencing result was read by DNA Baser software. The sequence clarified by NBLAST online from NCBI website (www.ncbi. nlm.nih.gov). The sequence mutation analyzed by Clustal-X2. DNA sequence was translated in to amino acid sequence using BioEdit software. The amino acid composition visualized into protein by PHYRE $^{2}$ Fold Recognition Server (www.sbg.bio.ic.ac.uk) and protein model was analyzed by PyMOL software.

\section{Results}

\subsection{OsDREB2A Gene Amplification Result}

The amplification resulted $840 \mathrm{bp}, 836 \mathrm{bp}$, and 850 bp length target gene fragments from Tambleng, Bulu Putih, and Pare Caok varieties, respectively (Figure 1). BLAST analysis has confirmed that obtained fragments are OSDREB2A gene with 95\% query coverage and

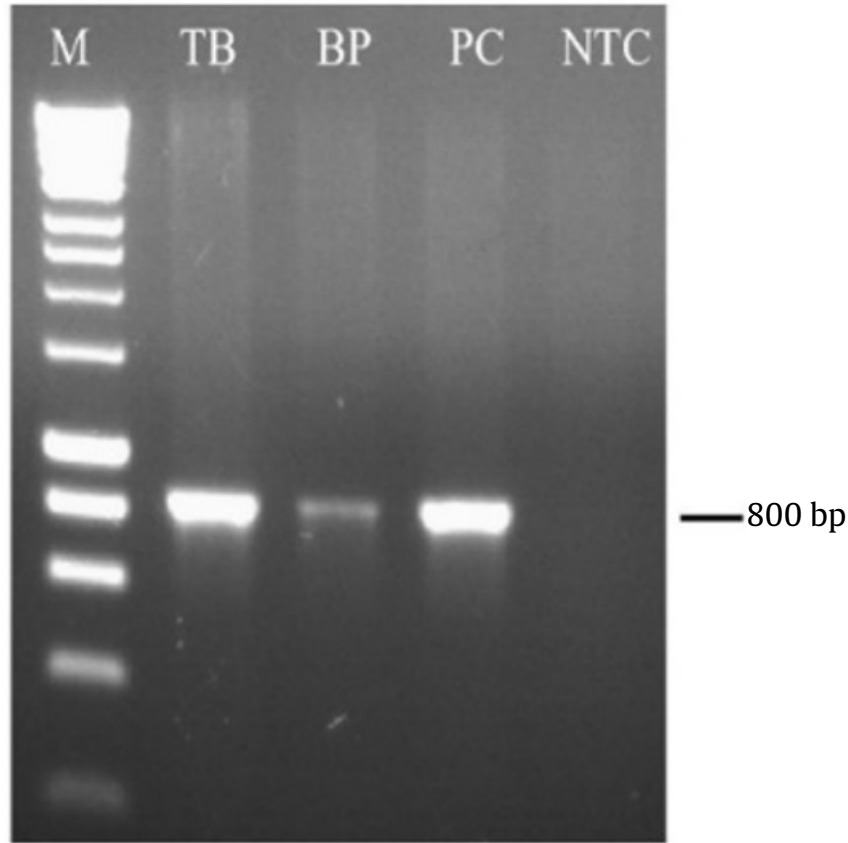

Figure 1. Electrophoresis visualization of OsDREB2A gene fragments amplified from Banten local rice varieties. M: 1kb DNA marker, TB: Tambleng variety, BP: Bulu Putih variety, PC: Pare Caok varieties, NTC: Non-template control

99.76\% similarity compared to Oryza sativa Indica Group cultivar RP Bio-226 chromosome 1 sequence (CP012609.1), Oryza sativa Indica Group cultivar Pokkali dehydration responsive element binding protein $2 \mathrm{a}$ (DREB2A) mRNA complete cds (JQ341059.1), and Oryza sativa Indica Group DREB-like protein (DREB1) gene, complete cds (HM807364.1), as well (Table 1).

Multiple alignment of target gene sequences with OsDREB2A sequence from Pokkali variety (NCBI Voucher No JQ341059.1) as a reference revealed that the sequence of OsDREB2A from the studied varieties housing few mutations with major part was conserved. The conserved sequence spent the length of fragments from base 19 up to base 838 (Figure 2). Tambleng have the same sequence with the others and there is a deletion of Thymine (bases number 18) and an insertion of cytosine (bases number 839).

\subsection{OsDREB2A Protein Polymorphism}

Insertion and deletion in OsDREB2A gene of Tambleng variety make different amino acid sequence compared with other varieties (Figure 3). Tambleng and Bulu Putih varieties do not have a start and stop codon but we found the start and stop codon in OsDREB2A sequence of Pare Caok variety. This amino acid sequence visualized by PHYRE $^{2}$ webserver to get protein models. 
Table 1. BLAST analysis of amplified OsDREB2A sequences from Tambleng, Bulu Putih, and Pare Caok variety with OsDREB2A sequence of Pokkali variety (JQ341059.1) as a reference

\begin{tabular}{lcccccc}
\hline Description & Max score & Total score & $\begin{array}{c}\text { Query cover* } \\
(\%)\end{array}$ & E value & $\begin{array}{c}\text { Perc. Id** } \\
(\%)\end{array}$ & $\begin{array}{l}\text { Accession } \\
\text { number }\end{array}$ \\
\hline Tambleng & 1541 & 1541 & 95 & 0.0 & 99.76 & JQ341059.1 \\
Bulu Putih & 1541 & 1541 & 95 & 0.0 & 99.76 & JQ341059.1 \\
Pare Caok & 1541 & 1541 & 95 & 0.0 & 99.76 & JQ341059.1 \\
\hline
\end{tabular}

Source: BLAST NCBI 2019

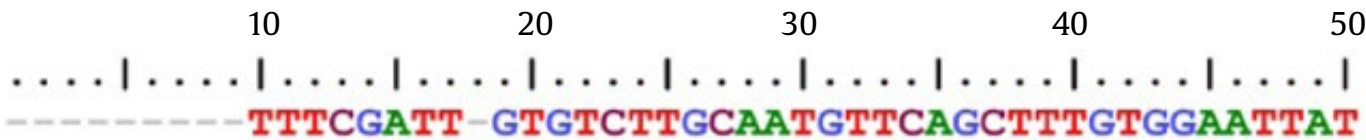

Tambleng TTCGATTTGTGTCTTGCAATGTTCAGCTTTGTGGAATTAT

Pare Caok ATGGTGGTTTTCGATTTGTGTCTTGCAATGTTCAGCTTTGTGGAATTAT Pokkali ATG--CTGTTTCGATTTGTGTCTTGCAATGTTCAGCTTTGTGGAATTAT

60

70

80

70

100

Tambleng

$\ldots|\ldots| \ldots|\ldots| \ldots|\ldots| \ldots|\ldots| \ldots|\ldots| \ldots \mid$

Bulu Putih

TGAGTTACCTCATTGGGTCAGGAAGAAGAGAACGCGAAGGAAAAGCGATG

Pare Caok

TGAGTTACCTCATTGGGTCAGGAAGAAGAGAACGCGAAGGAAAAGCGATG

Pokkali

TGAGTTACCTCATTGGGTCAGGAAGAAGAGAACGCGAAGGAAAAGCGATG TGAGTTACCTCATTGGGTCAGGAAGAAGAGAACGCGAAGGAAAAGCGATG

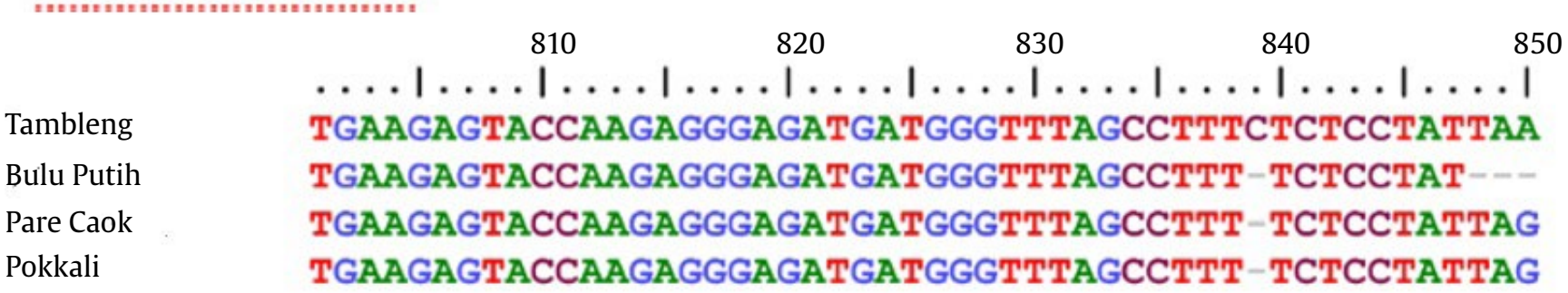

Tambleng

Bulu Putih

Pare Caok

Pokkali

Figure 2. OsDREB2A sequence comparation of Tambleng, Bulu Putih, and Pare Caok, toward Pokkali as a reference. Red double-dash line $(=====)$ depicts a leap of sequence due to its excessive length

Modeling results of the OsDREB2A protein through PHYRE2 shows a homologous protein model of the three sample varieties and consists of $3 \beta$-strand, $4 \alpha$-helix, and several coil structures (Figure 4). However, there is an extension of the coil structure in the Tambleng variety which has an impact on slight changes in the conformation of the $\beta$-strand structure. The insertion and change of the structure of $\beta$-strand OsDREB2A cannot be used as a benchmark for the height or low ability of a plant to survive on salinity stress due to other regulatory pathways that also play a role in the response to salinity stress.

OsDREB2A protein modeling result of Tambleng variety homologs with OsDREB2A protein from Pokkali with an amino acid extension in the downstream area of Tambleng variety protein model. That makes downstream coil structure of Tambleng protein model longer than Pokkali (Figure 5). The extension of the downstream coil structure causes the bonding distance between asparagine (ASN 97) and valine (VAL 193) in 


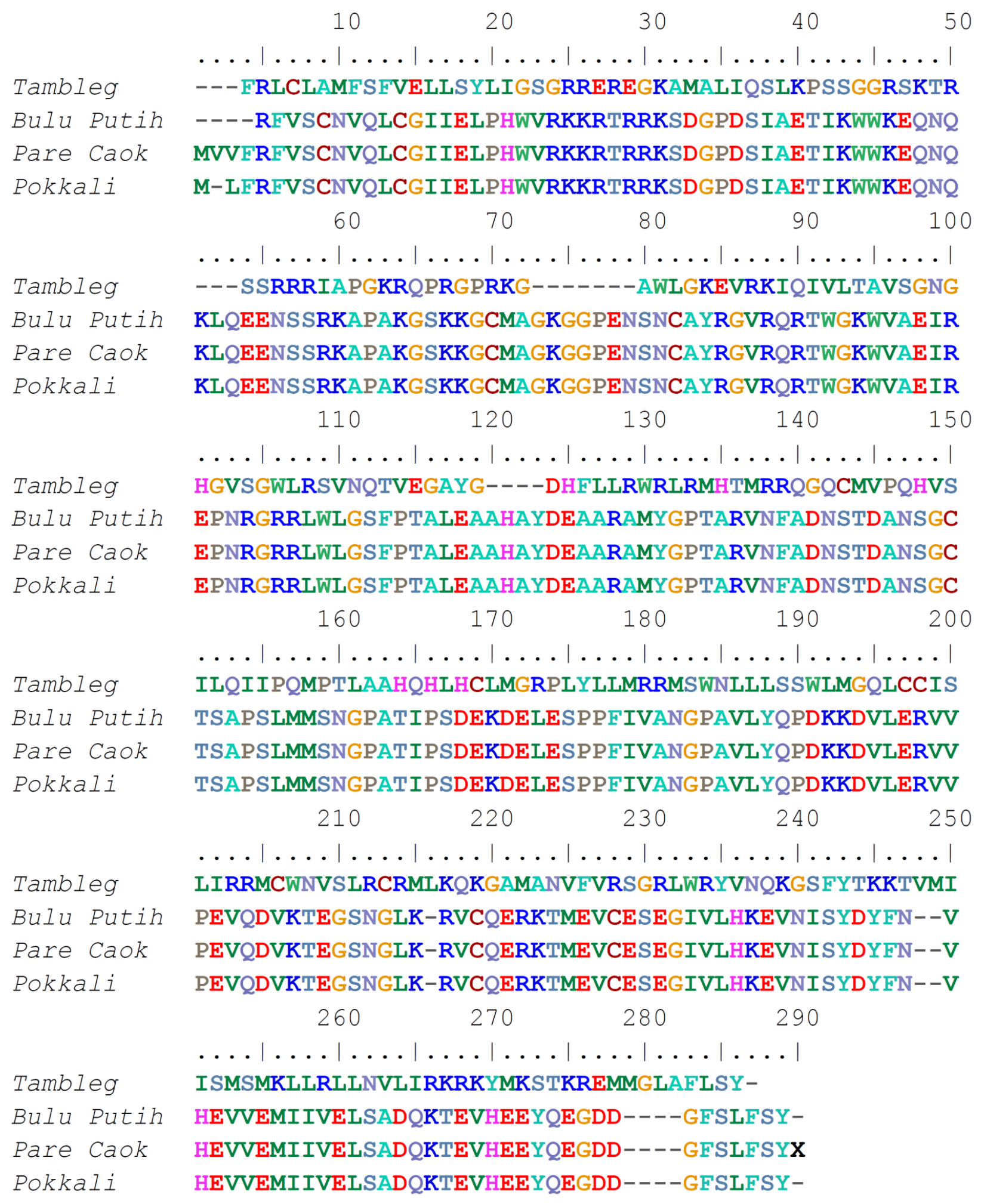

Figure 3. Multiple alignment of OsDREB2A amino acid sequences of Tambleng, Bulu Putih, and Pare Caok, with Pokkali's OsDREB2A amino acid sequence as a reference

Tambleng variety to be closer than in the Pokkali cultivar. The bonding distance between the asparagine and valine amino acids in Tambleng variety which is closer than
Pokkali cultivar causes changes in the conformation of $\beta$-strand structure number 3 in Tambleng variety (Figure 6). 

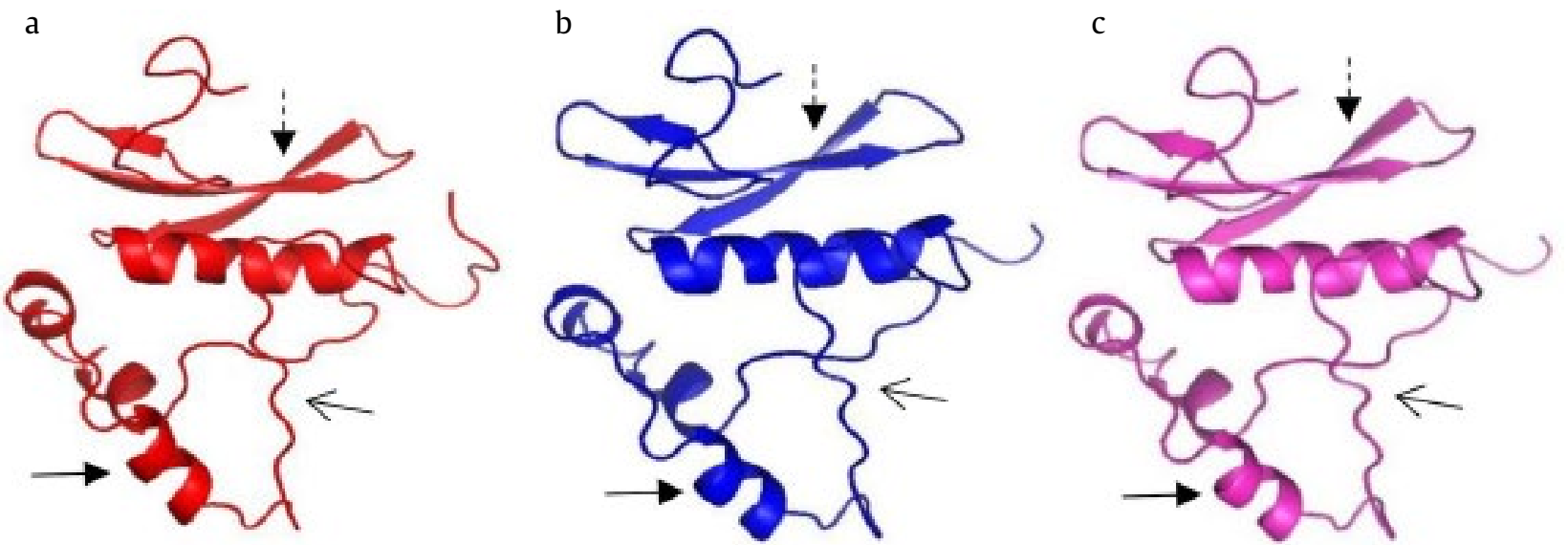

Figure 4. OsDREB2A protein model generated from OsDREB2A sequence of (a) Tambleng, (b) Bulu Putih, and (c) Pare Caok varieties, respectively. $\rightarrow: \alpha$-helix; $-\rightarrow: \beta$-strand; $\rightarrow$ : coil amino acid strand structures
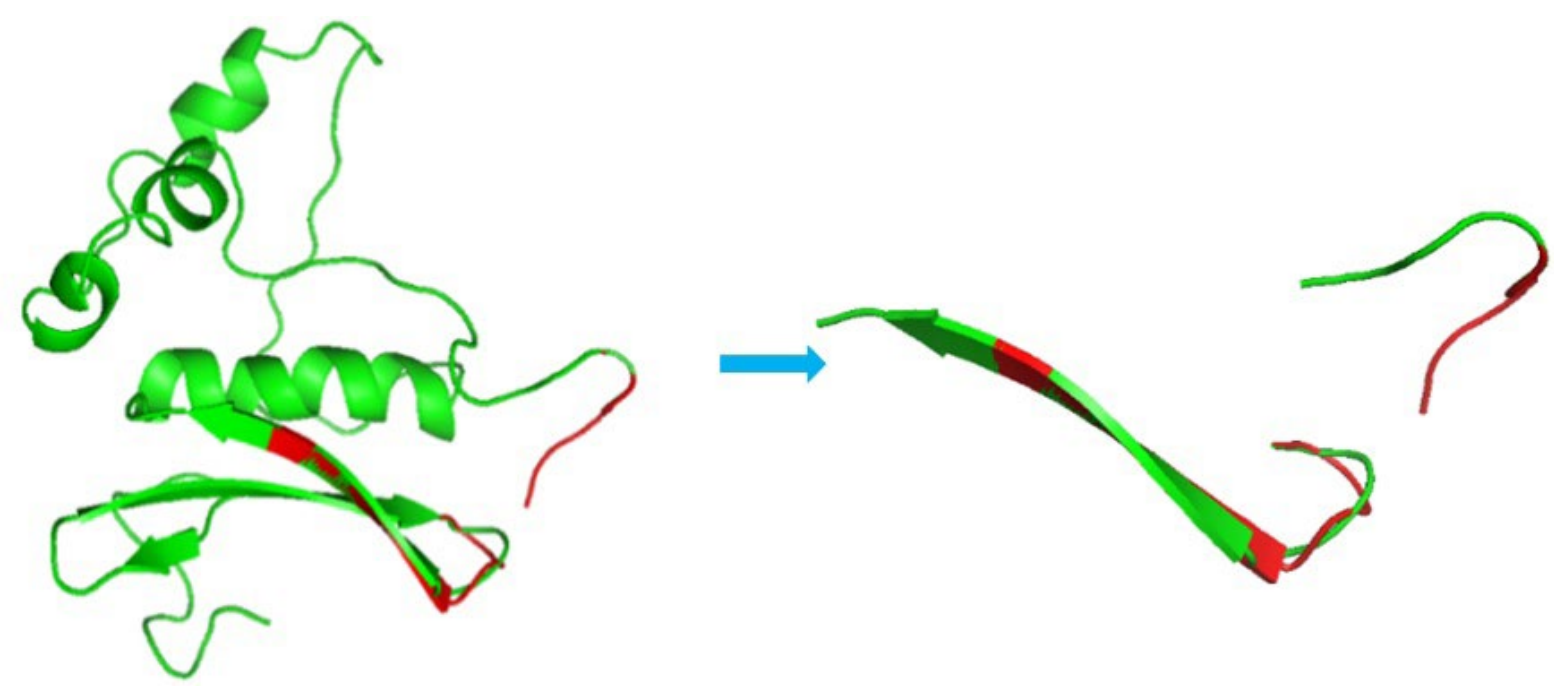

Figure 5. A vertical mirror projection from Figure 4 of Tambleng's and Pokkali's OsDREB2A protein model homology to show the alteration of this protein structure
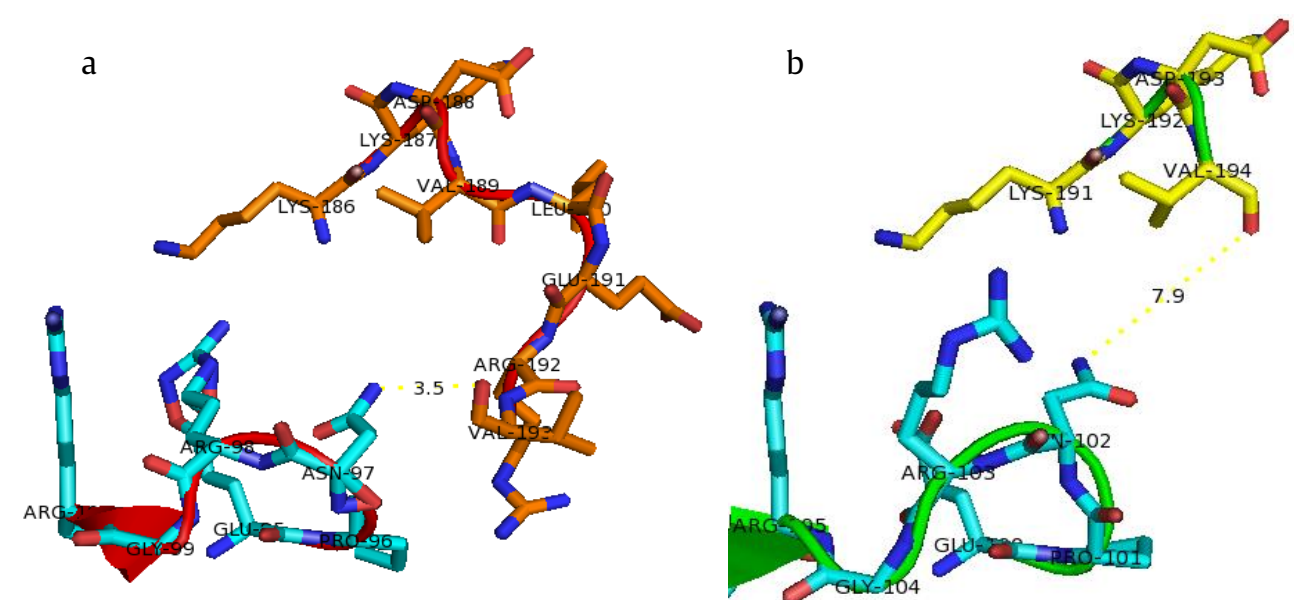

Figure 6. Valin and asparagine interaction in OSDREB2A protein models. Valin and asparagine spend $3.5 \AA$ and $7.9 \AA$ distance in both Tambleng's that makes different protein models conformation (a) and Pokkali's (b) protein model, respectively 


\section{Discussion}

OsDREB2A is a transcription factor from various genes that are active when bind to the DRE box (Yoshida et al. 2014). Some of the genes regulated by OsDREB2A including BADH2, CAN, HAL1, HSPs, and various genes involved in phytohormone regulation system. These genes work together to respond the salinity stress condition (Muchate et al. 2016).

Our work unveiled that the OsDREB2A polymorphism was occurred in three local rice varieties from Banten we studied. The mutation including insertion and deletion. Those mutations slightly affected OsDREB2A protein structure. In both Tambeng varieties the alteration occurred in one segment of $\beta$-sheet and in some coil segments. Furthermore, those changes also slightly affected on binding distance. Meanwhile, the mutation occurred in Bulu Putih and Pare Caok varieties did not change its protein structure. The $\beta$-sheet structure is a specific area for OsDREB2A binding to the target gene promoter known as DRE box (Chen et al. 2020). This domain works to regulate the expression of dehydration response genes in plants (Maruyama et al. 2012). Mutations in the $\beta$-sheet section are able to affect protein function (Abrusan and Marsh 2016) by decreasing the ability of OsDREB2A to bind the DRE box in the promoter region (Lathif et al. 2018) and in turn affects the expression of targeted genes (Kelley and Lawrence 2009).

The opposite was reported in Arabidopsis thaliana cases, there is no effect of OsDREB2A mutation on its protein function in the binding to the target protein (Chen et al. 2020). And in accordance to the fact that all three rice varieties we studied were agronomically proven in high salinity resistant (Ubaidillah and Siswoyo 2018) we suggest that OsDREB2A mutation occurred in those three varieties does not affect the function of OsDREB2A. Taking a consideration that OsDREB2A is a member of the APETALA2/Ethylene Responsive Factor (AP2/ERF) subgroup IVa gene family that functions in stress response (Oh et al. 2009) which preserved its conserved region (Nakano et al. 2006; Shanaka et al. 2014; Chen et al. 2020) and that this conserved region consists of DNA binding area and CMIV-1, CMIV-2 motifs which is a special characteristic of the AP2/ERF domain IVa gene group (Rini 2019; Nakano et al. 2006), we suggest that the mutation should be massive to be able to give the effect on the loss of saline resistant capability.

Since there are other regulatory pathways that play a role in the response to salinity stress in plants including the ABA-dependent pathway, SOS pathway, and ROS signaling pathway (Huang et al. 2012) and that the differences in the OsDREB2A expression level had been reported to be able to influence the tolerance level of plants to salinity conditions (Gumi et al. 2018), a lot more of works required to be done to understand how Tambleng, Bulu Putih, and Pare Caok rice varieties gain its ability to resist the salinity stress response. The expression and its down-stream pathways of OsDREB2A in those three rice varieties are two of many parameters should be addressed.

\section{Conclusion}

This study revealed the mutation of OsDREB2A which slightly affect its protein structure. The insertion changes its $\beta$-sheet structure but doesn't affect the DNA binding region. It also supports the agronomic proof in saline resistant potency of Tambleng, Bulu Putih, and Pare Caok. From this study we conclude that there is a polymorphism in OsDREB2A gene from Tambleng, Bulu Putih, and Pare Caok rice varieties. This polymorphism does not affect the saline resistance potency of those three studied varieties.

\section{Acknowledgements}

The authors would like to extend their high appreciation to the Universitas Sultan Ageng Tirtayasa 4in1 IsDB Biotechnology Research Consortium members for providing the samples. This work was supported by Central Laboratory of Mineral and Advanced Material FMIPA Universitas Negeri Malang and Genetic and Biomolecular Laboratory of UIN Maulana Malik Ibrahim Malang. This research is a part of 4in1 IsDB Biotechnology Research Consortium Project and funded by PIUPT Disruptive Learning Innovation of Universitas Negeri Malang to D.L. and S.

\section{References}

Abuelgasim A, Ammad R. 2019. Mapping soil salinity in arid and semi-arid region using landsat 8 OLI Satellite Data. Remote Sensing Applications: Society and Environment 13:415-425. DOI:10.1016/j.rsase.2018.12.010

Abrusan G, Marsh JA. 2016. Alpha helices are more robust to mutations than beta strands. PLoS Comput Biol 12:e1005242. DOI:10.1371/journal.pcbi.1005242

Chen CY et al. 2020. Structural insights into Arabidopsis ethylene response factor 96 with an extended $\mathrm{N}$-terminal binding to GCC box. Plant Mol Biol 104:483-498. DOI:10.1007/s11103-020-01052-5

Chinnusamy Vetal. 2006. Salt stress signaling and mechanisms of plant salt tolerance. Genetic Engineering 27:141-177.

Dubouzet JG et al. 2003. OsDREB genes in rice, Oryza sativa L., encode trnscription activators that function in drought-, high-salt- and cold-responsive gene expression. The Plant Journal 33:751-763. 
[FAO] Food and Agriculture Organization. 2003. Applications of Molecular Biology and Genomics to GeneticEnhancement of Crop Tolerance to Abiotic Stress A Discussion Document. Available at: https://cgspace.cgiar.org/ handle/10947/182 [Date accessed:22 December 2018]

Gumi AM et al. 2018. Characterization of OgIDREB2A gene from African Rice (Oryza glaberrima), comparative analysis and its transcriptional regulation under salinity stress. Biotech 8:1-16.

Huang GT et al. 2012. Signal transduction during cold, salt, and drought stresses in plant. Mol Biol Rep 39:369987. DOI:10.1007/s11033-011-0823-1

Jenks MA et al. 2007. Advance in Molecular Breeding toward Drought and Salt Tolerant Crops. Finland: Springer.

Kelley LA, Lawrence. 2009. Protein structure prediction on the web: a case study using the phyre server. Narure Protocol 4:363-371. DOI:10.1038/nprot.2009.2

Lathif Y et al. 2018. Varietas padi lokal Jawa Timur tahan cekaman kekeringan berdasarkan gene DREB2A. Biotropika: Journal of Tropical Biology 6:89-95.

Liu S et al. 2013. Genome-wide analysis of ZmDREB genes and their association with natural variation in drought tolerance at seedling stage of Zea mays L. PloS Genetics 9:1-18. DOI:10.1371/journal.pgen.1003790.

Maruyama $\mathrm{K}$ et al. 2012. Identification of cis-acting promotor elements in cold- and dehydrationinduced transcriptional pathways in arabidopsis rice, and soybean. DNA Research 19:37-49. DOI:10.1093/ dnares/dsr040

Matsukura S et al. 2010. Comprehensive analysis of rice DREB2-type genes that encode transcription factors involved in the expression of abiotic stress-responsive genes. Mol Genet Genomics 283:185-196. DOI:10.1007/ s00438-009-0506-y

Muchate NS et al. 2016. Plant salt stress: adaptive responses, tolerance mechanism and bioengineering for salt tolerance. The Botanical Review 82:371-406. DOI:10.1007/s12229-016-9173-y
Nakano T et al. 2006. Genome-wide analysis of the ERF gene family in arabidopsis and rice. Plant Physiology 140:411-432. DOI:10.1104/pp.105.073783

Oh S et al. 2009. Overexpression of the transcription factor AP37 in rice improves grain yield under drought condition. Plant Physiology 150:1368-1379. DOI:10.1104/pp.109.137554

RC Biotechnology. 2018. Biotechnology in Agriculture and Health Rice Cultivars Improvement Using Molecular Approach. Jakarta: Unpublished data.

Rini DS. 2019. Short communication: sequence variation of DREB2 gene as a potential molecular marker for identifying resistant plants toward drought stress. Nusantara Bioscience 11:35-43. DOI:10.13057| nusbiosci/n110107

Sakuma Y et al. 2002. DNA-binding specifity of the ERF/AP2 domain of arabidopsis DREBs, transcription factors involved in dehydration-and cold-inducible gene expression. Biochemical and Biophysical Research Communications 290:998-1009.

Shanaka WID et al. 2014. Identification, cloning, and In-Silico characterization of drought inducible OsDREB2A transcription factor from indica rice variety. International Journal of Advance Biotechnology and Research 5:117-125.

Shastry BS. 2009. SNPs: Impact on gene function and phenotype. Methods Mol Biol 578:3-22. DOI:10.1007/978-1-60327-411-1_1

Ubaidillah M, Siswoyo TA. 2018. Buku Deskripsi Plasma Nutfah Padi Indonesia. Yogyakarta: CV. Budi Utama.

Yoshida T et al. 2014. ABA-dependent and ABA-independent signalling in response to osmotic stress in plants. Current Opinion in Plant Biology 21:133-139. DOI:10.1016/j.pbi.2014.07.009 